\title{
Immunochemical Characterization of Variant Long-Chain Acyl-CoA Dehydrogenase in Cultured Fibroblasts from Nine Patients with Long-Chain Acyl-CoA Dehydrogenase Deficiency
}

\author{
YASUHIRO INDO, ${ }^{1}$ PAUL M. COATES, DANIEL E. HALE, AND KAY TANAKA \\ Yale University School of Medicine, Department of Human Genetics, New Haven, Connecticut 06510 [Y.I., K.T.] \\ and University of Pennsylvania School of Medicine, Department of Pediatrics, Gastroenterology/Nutrition \\ [P.M.C.] and Endocrine/Diabetes [D.E.H.] Divisions, The Children's Hospital of Philadelphia, \\ Philadelphia, Pennsylvania 19104
}

\begin{abstract}
Long-chain acyl-CoA dehydrogenase (LCAD) deficiency is a disorder of mitochondrial fatty acid oxidation that is characterized by hypoglycemia, muscle weakness, and hepato- and cardiomegaly. To characterize variant LCAD, we first carried out preliminary experiments using pure enzyme preparations. Despite the significant sequence similarity of LCAD to medium-chain acylCoA dehydrogenase, the antibody raised against rat LCAD was monospecific for human and rat LCAD and did not cross-react with either human or rat medium-chain acylCoA dehydrogenase. Immunoblot analysis of variant LCAD in cultured fibroblasts from nine patients with LCAD deficiency revealed a single LCAD band in all nine LCAD-deficient cell lines. Each variant LCAD was comparable in molecular size and quantity to normal LCAD, suggesting that the LCAD mutation in each of these cell lines is likely to be a point mutation that produces a stable variant $L C A D$. The uniform nature of variant $L C A D$ suggests that only a single, or at most a few, prevalent point mutations may be found in the majority of LCAD-deficient patients. If this is the case, it should be possible to devise a molecular diagnostic method for LCAD deficiency. (Pediatr Res 30: 211-215, 1991)
\end{abstract}

\section{Abbreviations}

LCAD, long-chain acyl-CoA dehydrogenase MCAD, medium-chain acyl-CoA dehydrogenase SCAD, short-chain acyl-CoA dehydrogenase

LCAD deficiency is an autosomal recessive disorder of fatty acid metabolism. It was first described in three infants in 1985 by Hale et al. (1). Subsequently, 11 additional patients have been identified (2). The main clinical features seen in these patients were severe hypoglycemia, skeletal muscle weakness, and hepatomegaly; cardiomegaly was a significant feature in eight patients. Six of them died in early infancy; however, the clinical manifestations in some other cases were much milder $(1,2)$, suggesting

Received January 14, 1991; accepted May 13, 1991.

Correspondence and reprint requests: Kay Tanaka, M.D., Yale University School of Medicine, Department of Human Genetics, 333 Cedar Street, P.O. Box 3333, New Haven, CT 06510.

Supported by grants (DK38154 and NS17752) from the National Institutes of Health.

Present address: Kumamoto University Medical School, Department of Pediatrics, Honjo 1-1-1, Kumamoto City 860 , Japan. heterogeneity. Heterogeneity of LCAD deficiency was also suggested by a biochemical assay (3). As in the case of MCAD deficiency (4), some patients with LCAD deficiency abruptly died with few prodromal symptoms, mimicking sudden infant death syndrome (5). No urinary metabolites are specific for this disease, making it difficult to establish the diagnosis. At present, the diagnosis of LCAD deficiency is made by the assay of LCAD activity in cells such as fibroblasts and leukocytes or in solid tissues; however, methods for the assay of LCAD and other acyl$\mathrm{CoA}$ dehydrogenase activities are cumbersome and time-consuming.

As the first step in the molecular characterization of mutations of human LCAD that cause LCAD deficiency, we studied the variant LCAD protein in cultured fibroblasts from nine patients with LCAD deficiency using immunoblot analysis.

\section{MATERIALS AND METHODS}

Materials. Purification of MCAD and LCAD from rat liver mitochondria and the preparation of the respective antibodies were previously reported by Ikeda et al. (6). These antibodies also recognized the respective human enzymes as well (7). Purification of human MCAD was reported by Finocchiaro et al. (8). Tissue culture materials were obtained from GIBCO (Grand Island, NY). Inactivated Staphylococcus aureus cells were from Bethesda Research Laboratories (Gaithersburg, MD).

Source of fibroblast cultures. Cell cultures were obtained from nine unrelated LCAD-deficient patients who have been reported previously $(1,2)$. All patients were unrelated. The identification of the LCAD-deficient cells is as follows: YH1414, J-1; YH1418, $\mathrm{A}-1$; and $\mathrm{YH} 1435, \mathrm{R}-1$, as reported in reference 1 . The identification numbers of the six other LCAD-deficient cell lines are identical to those in the original report (2), except that each number is preceded by the two letters CP. The deficiency of LCAD activity in these cells was confirmed using the electron transfer flavoprotein-dependent fluorometric assay. Clinically, YH1414, YH1418, YH1435, CP2, CP3, and CP8 belong to the first type, which is characterized by early onset, high mortality, and cardiac involvement. CP9 and CP11 belong to the second type, which is acute and of early onset but presents no cardiac dysfunction or muscle weakness. $\mathrm{C} 14$ belongs to the third type, which is characterized by a late onset (2). Normal cell cultures were obtained from the Human Genetic Mutant Cell Repository (Camden, NJ).

Cell culture and protein chemistry. Cell culture and extraction of cell proteins were carried out as previously described (9). The protein concentration was determined by the method of Branford (10) using bovine gamma globulin as a standard. 
Immunoabsorption of pure enzyme preparations and cell extracts with antibody. The indicated amount of pure enzyme preparations was dissolved in $100 \mu \mathrm{L}$ of the extraction buffer, to which $0.1 \%$ BSA was added as a carrier. The enzyme solution was mixed with $2-\mu \mathrm{L}$ of the antibody against the enzyme to be removed and left at $4^{\circ} \mathrm{C}$ overnight. In the case of cell extracts, insoluble materials were first removed by centrifugation, and the supernatant was similarly treated with antibody. Fifty $\mu \mathrm{L}$ of $10 \%$ $S$. aureus suspension were then added, and allowed to react for $15 \mathrm{~min}$ at room temperature. The immune complex bound to $S$. aureus cells was removed by centrifugation. The supernatant was used for further analysis by SDS-PAGE.

SDS-PAGE and immunoblot analysis. SDS-PAGE was carried out on $10 \%$ polyacrylamide-gel slabs with a $5 \%$ stacking gel, using the discontinuous buffer system described by Laemmli (11). When pure enzyme was used as standard, $1 \mathrm{mg} / \mathrm{mL}$ of BSA was included in the standard solution to avoid the loss of antigen due to adsorption. After electrophoresis, gel was electroblotted onto a nitrocellulose (Schleicher and Schuell, Keene, NH) or Immobilon-P sheet (Millipore, Bedford, MA), according to the method described by Towbin et al. (12). The blot was treated as described previously (13), except that incubation with the specific antibody was done for $1 \mathrm{~h}$. The antigen/antibody complex was detected using the alkaline phosphatase-conjugated goat antirabbit IgG system (Bio-Rad Laboratories, Richmond, CA).

\section{RESULTS}

Characterization of interactions of rat and human LCAD and $M C A D$ with homologous and heterologous antibodies raised against rat enzymes. We previously observed that, unlike other human acyl-COA dehydrogenases, human LCAD was not immunoprecipitated as native protein by the antibody raised against its rat counterpart (7). Therefore, $\left[{ }^{35} \mathrm{~S}\right]$ methionine-labeling/immunoprecipitation of human LCAD could not be performed. However, we subsequently found that immunoblotted human LCAD was strongly recognized by anti-rat LCAD antibody, possibly due to unfolding of the protein by SDS.

To characterize the immunoreactions of LCAD and MCAD, both human and rat, we first carried out three sets of preliminary experiments with the pertinent antibodies for the following reasons. First, although rat LCAD did not cross-react with antiMCAD antibody nor did MCAD cross-react with anti-LCAD antibody as native proteins (6), their cross-reactivity in the denatured state was unknown. Furthermore, the electrophoretic mobility of authentic human LCAD was unknown, inasmuch as human LCAD has never been purified. The electrophoretic mobilities of rat LCAD and MCAD were indistinguishable, but other acyl-CoA dehydrogenases can be readily distinguished from each other by slight but distinct differences in their electrophoretic mobility (6).

In the first set of experiments, we carried out immunoabsorption experiments using the purified rat enzymes to test whether it is necessary to remove a small amount of contaminating enzyme that may be present in the purified LCAD or MCAD preparations and may interfere with the immunoreactions. These experiments served also to characterize the specificity of antibodies toward denatured acyl-CoA dehydrogenases. We first carried out preabsorption of pure rat MCAD by incubating it with antiLCAD antibody or preimmune serum, followed by mixing with $S$. aureus cell suspension; in this system, the immune complex binds to Protein A in $S$. aureus cells and precipitates. The supernatant was electrophoresed and electroblotted, and the proteins detected using anti-MCAD antibody as probe. When the pure rat MCAD preparation ${ }^{2}$ was directly applied to the gel

${ }^{2}$ Despite their high purity, most of the rat and human MCAD preparations exhibited double bands when analyzed on SDS-PAGE $(6,8)$. The double bands can be immunoprecipitated by anti-rat MCAD antibody with equal deficiency, indicating their identity. The determination of the amino terminal sequence indicated that the double band is due to a loss of several amino acid residues from the amino terminus in some of the MCAD molecules (6) without preabsorption, MCAD above the amount of $10 \mathrm{ng}$ was readily detectable (Fig. $1 A$, lanes 1 and 2 ). When 133 and 13.3 ng of pure rat MCAD were subjected to preabsorption with preimmune serum followed by electrophoresis and electroblot, a recognizable loss of MCAD occurred, but both bands were readily detectable (Fig. $1 A$, lanes 3 and 5 ). When the same amounts of the MCAD preparation were preabsorbed with antiLCAD antibody, the amount of MCAD detected was comparable
A

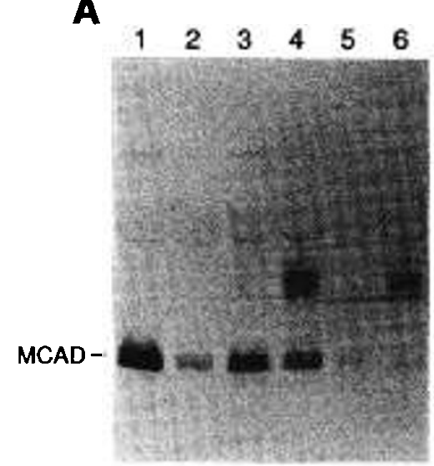

B

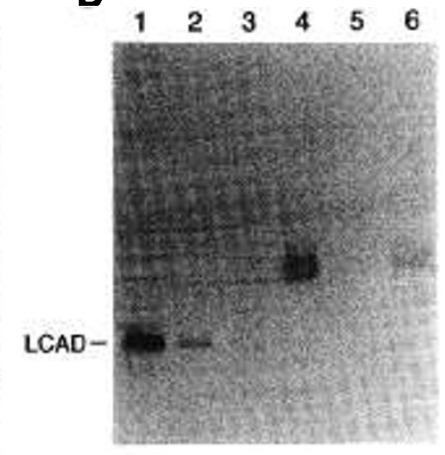

C $\begin{array}{lllllll}1 & 2 & 3 & 4 & 5 & 6 & 7\end{array}$

Fig. 1. Characterization of antibody by preabsorption and immunoblot analysis. Pure enzymes (400 or $40 \mathrm{ng}$ ) in $100 \mu \mathrm{L}$ of buffer were preabsorbed with $2 \mu \mathrm{L}$ of preimmune, anti-MCAD, or anti-LCAD antibody, followed by mixing with $50 \mu \mathrm{L}$ of $10 \% S$. aureus suspension and centrifugation. One third of each supernatant was subjected to immunoblot analysis as described in Materials and Methods. $A$, Immunodetection of purified rat MCAD using anti-MCAD antibody as a probe with and without preabsorption with anti-LCAD antibody. Lanes 1 and 2, 100 and $10 \mathrm{ng}$, respectively, of purified rat MCAD were directly applied as standard; lanes 3 and 4, 133 ng of rat MCAD after preabsorption with preimmune rabbit serum and anti-LCAD antibody, respectively; lanes 5 and $6,13.3 \mathrm{ng}$ of rat MCAD after preabsorption with preimmune rabbit serum and anti-LCAD antibody, respectively. The intense bands above the MCAD bands (lanes 3-6) are the heavy chain of IgG derived from the preimmune serum or the antibodies used. The broad, faint bands seen in each lane are a result of BSA being used as a carrier. $B$, Immunodetection of purified rat MCAD using anti-LCAD antibody as a probe after preabsorption with anti-LCAD antibody. This experiment was designed to test whether the rat MCAD preparation is cross-reactive to anti-LCAD antibody. Lanes 1 and 2, 100 and $10 \mathrm{ng}$, respectively, of purified rat LCAD were directly applied as an electrophoretic standard; lanes 3 and 4, $133 \mathrm{ng}$ of purified rat MCAD after preabsorption with preimmune rabbit serum and anti-LCAD antibody, respectively; lanes 5 and 6, $13.3 \mathrm{ng}$ of pure rat MCAD after preabsorption with preimmune rabbit serum and anti-LCAD antibody, respectively. $C$, Immunodetection of purified rat LCAD, with and without preabsorption with anti-LCAD antibody, using anti-LCAD antibody as a probe. Lane $1,15 \mathrm{ng}$ of rat LCAD was directly applied as a standard; lanes 2 and 3 , 133 and $13.3 \mathrm{ng}$, respectively, of rat LCAD after preabsorption with preimmune rabbit serum; lanes 4 and 5, 133 and $13.3 \mathrm{ng}$, respectively, of pure rat LCAD after preabsorption with anti-MCAD antibody; lanes 6 and 7,133 and $13.3 \mathrm{ng}$, respectively, of pure rat LCAD after preabsorption with anti-LCAD antibody. 
to that detected after absorption with preimmune serum (Fig. $1 A$, lanes 4 and 6 ), indicating that anti-LCAD antibody does not precipitate rat MCAD.

In the second experiment of this set, the same aliquots of the same MCAD preparation were analyzed by electrophoresis and electroblotted in the same manner as in the first experiment, but immunodetection of proteins was done using anti-LCAD antibody as a probe (Fig. $1 B$ ). In lanes $l$ and 2, 100 and $10 \mathrm{ng}$, respectively, of the purified rat LCAD preparation was directly applied to SDS-PAGE as a standard without preabsorption. When the rat MCAD preparation was preabsorbed with either anti-LCAD antibody or preimmune serum and probed with antiLCAD antibody, no band was detectable (Fig. 1B, lanes 3-6), indicating that rat MCAD, even at $133 \mathrm{ng}$, did not cross-react with anti-LCAD antibody. In the third experiment, the rat LCAD preparation was immunoblotted after preabsorption with preimmune serum (lanes 2 and 3), anti-MCAD (lanes 4 and5) or antiLCAD antibody (lanes 6 and 7), and probed with anti-LCAD antibody (Fig. $1 C$ ). In lane $1,15 \mathrm{ng}$ of pure rat LCAD was directly applied to the gel as a standard. As can be seen in lanes 6 and 7,133 and $13.3 \mathrm{ng}$ of rat LCAD was completely removed by preabsorption with $2 \mu \mathrm{L}$ anti-LCAD antibody, indicating the strong potency of this antibody. In contrast, no detectable amount of rat LCAD was removed by preabsorption with preimmune serum (lanes 3 and 4 ) or anti-MCAD antibody (lanes 4 and 5). These results demonstrate that the antibodies used in this study were indeed monospecific and potent.

In the second set of experiments, immunotitration of rat LCAD (Fig. $2 A$ ) and MCAD (Fig. $2 B$ ) was carried out using a serially diluted crude rat liver mitochondrial extract as antigen. Preabsorption with $2 \mu \mathrm{L}$ of anti-LCAD antibody removed most of the LCAD from the mitochondrial extract containing 50 and $25 \mu \mathrm{g}$ protein, and all of the LCAD from the mitochondrial extract containing $12.5 \mu \mathrm{g}$ protein (Fig. $2 A$, row $a$ ). However preabsorption with anti-MCAD antibody did not reduce LCAD to any recognizable degree (Fig. $2 A$, row $b$ ). Preabsorption with $2 \mu \mathrm{L}$ of anti-MCAD antibody similarly removed most of the MCAD proteins from mitochondrial extracts containing $25 \mu \mathrm{g}$ protein and all of the MCAD from mitochondrial extracts containing $6.25 \mu \mathrm{g}$ protein (Fig. $2 \mathrm{~B}$, row $\mathrm{a}$ ), but preabsorption with anti-LCAD antibody did not reduce the amount of MCAD (Fig. $2 B$, row $b$ ). These results again demonstrated the high specificity and strong potency of the antibodies used in the present study.

In the third set of experiments, we tested the cross-reactivity of human MCAD with anti-LCAD antibody. The purified human MCAD preparation was probed with anti-MCAD (Fig. $3 A$ ) or anti-LCAD antibody (Fig. $3 B$ ) with and without preabsorption with anti-MCAD antibody. The data shown in Figure $3 A$ demonstrate that considerably more than $40 \mathrm{ng}$ of MCAD could be precipitated with $2 \mu \mathrm{L}$ of anti-MCAD antibody. No band could be detected with anti-LCAD antibody either with or without preabsorption with anti-MCAD antibody (Fig. $3 B$ ). Similar experiments on human LCAD could not be carried out because it has not been purified.

Analysis of skin fibroblasts from patients with $L C A D$ deficiency. First, immunoreactive LCAD and MCAD proteins in cultured skin fibroblasts from the three LCAD-deficient patients originally described by Hale et al. (1) were analyzed with and without preabsorption with anti-MCAD antibody (Fig. 4, $A$ and $B$ ). For comparison, a normal (GM05756) and an MCADdeficient cell line (YH1475) were included in this experiment. When immunoblots were probed with anti-LCAD antibody, all three LCAD-deficient cells showed a clear single variant LCAD band that was indistinguishable in size from normal LCAD. The mobility of the LCAD band in the cell extract appeared slightly slower than that of pure rat LCAD on SDS-PAGE. The intensity of variant LCAD bands in the three LCAD-deficient cell lines was also similar to that in normal cells. When the same samples were analyzed for MCAD protein without preabsorption with anti-MCAD antibody, a normal MCAD band was detected in
A

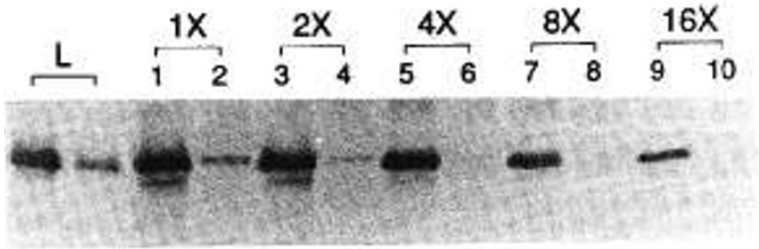

b

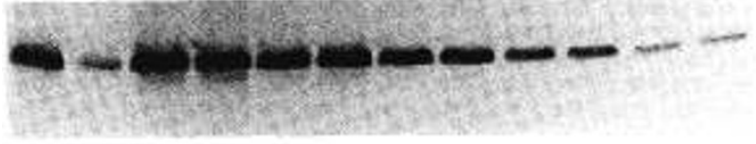

B

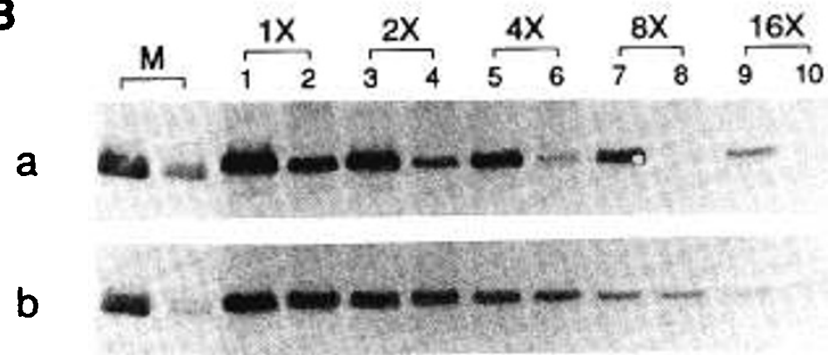

Fig. 2. Immunotitration of rat mitochondrial extract: characterization of antibodies. Serial 2-fold dilutions of a rat mitochondrial extract containing $50 \mu \mathrm{g}$ of protein were preabsorbed with an appropriate antibody, and one third of each supernatant was subjected to immunoblot analysis. In each panel, 100 and $10 \mathrm{ng}$ of an appropriate purified rat enzyme ( $L, \mathrm{LCAD} ; M, \mathrm{MCAD})$ were applied at the left end. The degree of dilution is indicated at the top. $A$, Detection of LCAD using antiLCAD antibody as a probe. a, After preabsorption with preimmune rabbit serum (odd-numbered lanes) or anti-LCAD antibody (even-numbered lanes). $b$, After preabsorption with preimmune rabbit serum (oddnumbered lanes) or anti-MCAD antibody (even-numbered lanes). $L, 100$ $\mathrm{ng}$ and $10 \mathrm{ng}$ of rat LCAD. $B$, Detection of MCAD using anti-MCAD antibody as a probe. $a$, After preabsorption with preimmune rabbit serum (odd-numbered lanes) or anti-MCAD antibody (even-numbered lanes). $b$, After preabsorption with preimmune rabbit serum (odd-numbered lanes) or anti-LCAD antibody (even-numbered lanes). $M, 100$ and $10 \mathrm{ng}$ of rat MCAD.
A

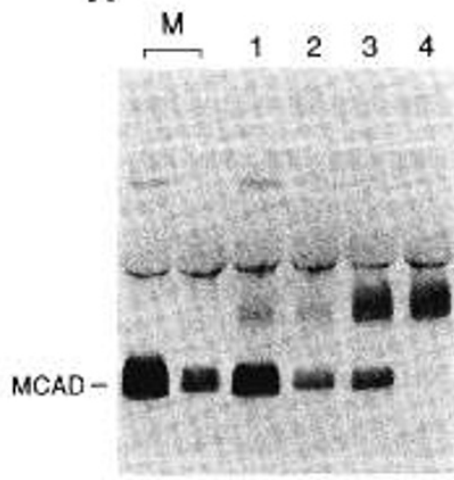

B

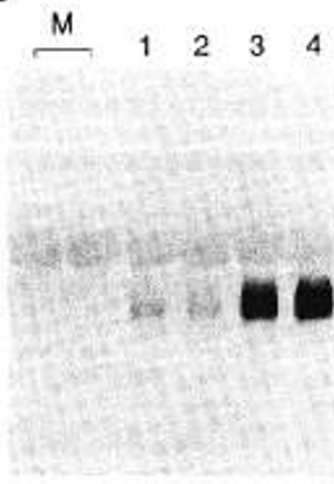

Fig. 3. Immunoreactions of human MCAD with anti-rat $\operatorname{MCAD}(A)$ and anti-rat LCAD antibodies $(B)$. $A$, Pure human MCAD (133 and 13.3 $\mathrm{ng}$ ) was detected using anti-MCAD antibody as a probe after preabsorption with preimmune rabbit serum (lanes 1 and 2) or anti-MCAD (lanes 3 and 4) antibody. $M, 133$ and $13.3 \mathrm{ng}$ of human MCAD were directly applied as standard. $B$, Pure human MCAD (133 and $13.3 \mathrm{ng}$ ) was probed with anti-LCAD antibody probe after preabsorption with preimmune rabbit serum (lanes 1 and 2) or anti-MCAD (lanes 3 and 4) antibody. $M, 133$ and $13.3 \mathrm{ng}$ of human MCAD were directly applied as standard. 
A

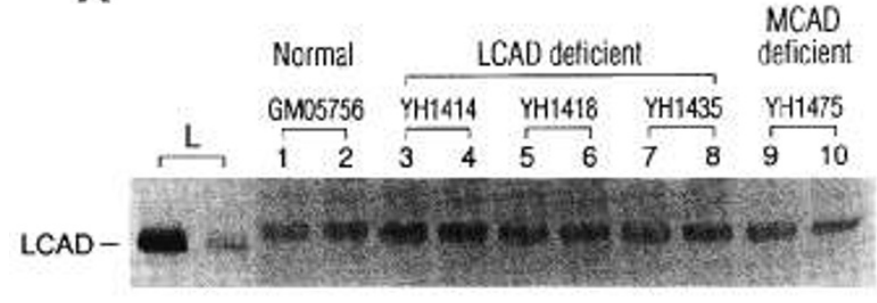

B

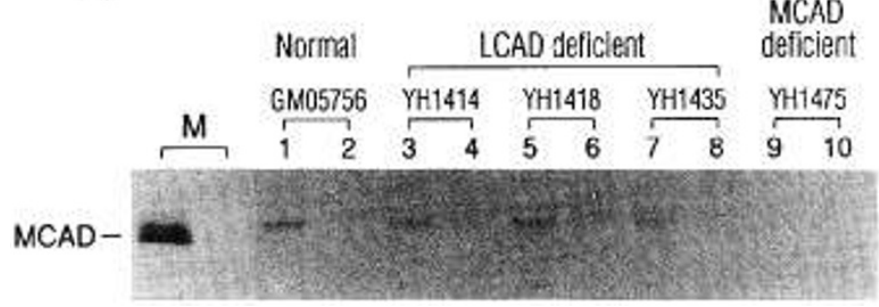

Fig. 4. Immunoblot analysis of variant LCAD in skin fibroblasts from three patients with LCAD deficiency. A confluent culture of normal or mutant fibroblasts in two $150-\mathrm{cm}^{2}$ flasks was harvested and treated with a detergent. The cell extract ( $300 \mu \mathrm{g}$ protein in $100 \mu \mathrm{L}$ ) was preabsorbed with preimmune rabbit serum (odd-numbered lanes) or anti-MCAD antibody (even-numbered lanes). One third of each supernatant was subjected to the immunoblot analysis. $A$, LCAD detected using antiLCAD antibody as a probe; $B$, MCAD detected using anti-MCAD antibody as a probe. At the left side of each panel, 100 and $10 \mathrm{ng}$ of a purified rat enzyme are spotted. $L, \mathrm{LCAD} ; M, \mathrm{MCAD}$.

A
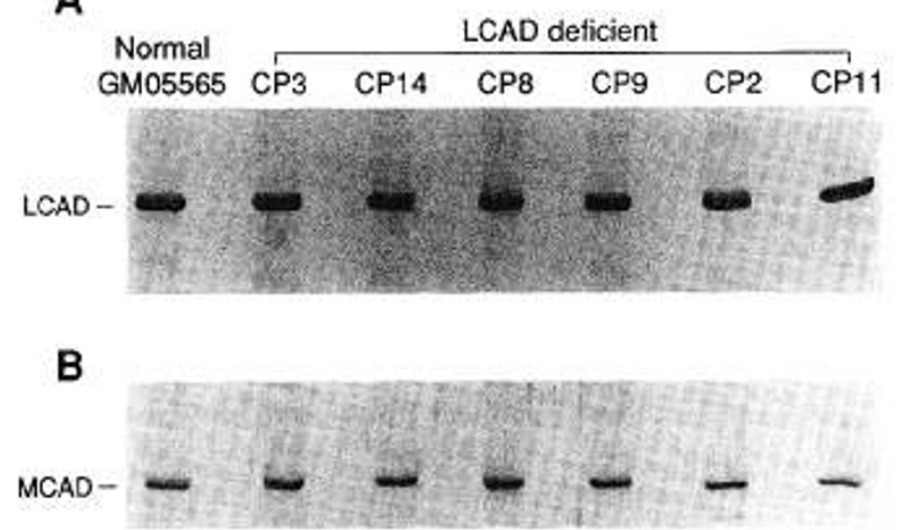

Fig. 5. Immunoblot analysis of variant LCAD in six additional LCAD-deficient cell lines. The skin fibroblast extract (100 $\mu \mathrm{g}$ protein) was subjected to the immunoblot analysis without preabsorption with antibodies. $A$, Variant LCAD detected using anti-LCAD antibody as a probe; $B$, MCAD detected using anti-MCAD antibody as a probe.

the normal and the three LCAD-deficient cell lines, but the MCAD band was detectable in none of them after preabsorption with anti-MCAD antibody. In the MCAD-deficient cells, no immunoreactive MCAD band was detectable even without preabsorption, indicating that YH1475 is negative for crossreactive materials. These data also provided evidence that LCAD and MCAD proteins were well distinguished in the present analytical system, despite the close sequence similarity (14-16; Indo Y, Glassberg R, Tanaka K, unpublished data).

Variant LCAD in six additional LCAD-deficient cell lines was further analyzed without preabsorption using anti-MCAD antibody as a probe (Fig. 5). Again, a single variant LCAD band was detected in all six cell lines. The molecular size was indistinguishable from and the amount was comparable to that of LCAD in normal cells.

\section{DISCUSSION}

There has been a controversy concerning whether LCAD and MCAD are immunologically cross-reactive. Previously, Furuta et al. (17) observed that their purified rat LCAD and MCAD proteins each cross-reacted with antibody raised against the other. We have subsequently demonstrated using immunotitration and Ouchterlony double diffusion methods (6) that none of our purified preparations of rat acyl-CoA dehydrogenases, including LCAD and MCAD, cross-reacted with antibodies raised against the other acyl-CoA dehydrogenases (6). The data presented here conclusively confirm that rat LCAD and MCAD are indeed immunologically distinct, not only in their native forms but also in their denatured forms. Thus, the cross-reactivity of rat LCAD and MCAD preparations with the respective antibodies observed by Furuta et al. (17) was due to cross-contamination of their preparations. Although human LCAD and MCAD are homologous, sharing $30.4 \%$ identical residues in their sequences (Indo $\mathrm{Y}$, Yang-Feng T, Glassberg R, Tanaka K, unpublished data), the present data suggest that they do not share common epitopes. This is probably because the stretches of consecutive identical amino acid residues shared by human LCAD and MCAD are short as in a pair of any two acyl-CoA dehydrogenases from the same species (17), usually extending only two to three residues, with the longest stretch being seven residues. In contrast, the stretches of consecutive identical amino acid residues shared by the same acyl-CoA dehydrogenase, including LCAD, from human and rat are generally much longer, often extending 15 to 17 residues. In the case of human and rat $\mathrm{LCAD}$, the longest stretch was 42 residues (Indo $\mathrm{Y}$, Yang-Feng T, Glassberg R, Tanaka K, unpublished data), rendering cross-reactivity to anti-rat LCAD antibody against human LCAD.

The characteristics of the variant LCAD protein studied here not only provide important insights into the nature of the biochemical basis of this disorder, but also contribute useful information for the molecular study of LCAD mutations. It was notable that the variant LCAD protein of normal size was detected in an amount comparable to normal in all nine unrelated LCAD-deficient cell lines regardless of their clinical phenotypes, suggesting that the LCAD mutation in these patients is likely to be a point mutation that produces a stable variant LCAD. This is in contrast to the findings with other acyl-CoA dehydrogenase deficiencies. In the study of 15 patients with isovaleric acidemia, at least five distinct types of variant isovaleryl-CoA dehydrogenase alleles were recognized with regard to the presence and absence of variant isovaleryl-CoA dehydrogenase proteins and their molecular size (18). In three known patients with SCAD deficiency, all variant SCAD were of normal size as tested with $\left[{ }^{35} \mathrm{~S}\right]$ methionine-labeling, suggesting that they are point mutations (19). However, the study of stability (9) and the sequence study (20) indicated that these SCAD mutations were extremely heterogenous. The pattern of variant MCAD is to some degree similar to that of variant LCAD. In the study of 13 MCAD-deficient cell lines, we previously showed using $\left[{ }^{35} \mathrm{~S}\right]$ methionine-labeling and immunoprecipitation that all of them synthesized a normal-size variant MCAD (21), but when one of these cell lines (YH1475) was tested by immunoblot analysis in the present study, no variant MCAD band was detectable, as shown in Figure 4. In the sequence study of nine independent MCAD-deficient cell lines including YH1475, a common point mutation, ${ }^{985} \mathrm{~A} \rightarrow \mathrm{G}$ transition, was detected in 17 variant alleles (22). In a subsequent study of 55 independent MCAD-deficient patients, we found that the prevalence of ${ }^{985} \mathrm{~A} \rightarrow \mathrm{G}$ was $89.1 \%$ of variant MCAD alleles (Yokota I, Coats PM, Hale DE, Rinaldo $\mathrm{P}$, Tanaka $\mathrm{K}$, unpublished results). Absence of cross-reactive variant MCAD in ${ }^{985} \mathrm{~A} \rightarrow \mathrm{G}$ homozygous cells have been confirmed in a much larger number of cell lines (Coates PM, Indo Y, Young D, Hale DE, Tanaka K, unpublished results).

The uniform nature of variant LCAD in terms of their size and stability suggests that only a single or a few prevalent point 
mutations may be found in the majority of LCAD-deficient patients. This is despite the apparent clinical and biochemical heterogeneity among patients. If this is the case, it should be possible to devise a fast molecular diagnostic method for LCAD deficiency that may make prompt diagnosis possible in most of the cases.

Acknowledgments. The authors thank Dr. Yasuyuki Ikeda for preparing the purified rat MCAD and LCAD, and antibodies against each, and Dr. Gaetano Finocchiaro for purifying the human MCAD. We thank Connie Woznick for preparing this manuscript.

\section{REFERENCES}

1. Hale DE Batshaw ML, Coates PM, Frerman FE, Goodman SI, Singh I, Stanley CA 1985 Long-chain acyl coenzyme A dehydrogenase deficiency: an inherited cause of nonketotic hypoglycemia. Pediatr Res 19:666-671

2. Hale DE, Stanley CA, Coates PM 1990 The long-chain acyl-CoA dehydrogenase deficiency. In: Tanaka K, Coates PM (eds) Fatty Acid Oxidation: Clinical, Biochemical and Molecular Aspects. Alan R Liss, Inc, New York, pp $303-$ 324

3. Amendt BA, Moon M, Teel L, Rhead WL 1988 Long-chain acyl-coenzyme A dehydrogenase deficiency: biochemical studies in fibroblasts from three patients. Pediatr Res 23:603-605

4. Roe CR, Coates PM 1989 Acyl-CoA dehydrogenase deficiencies. In: Scrive CR, Beaudet AL, Sly WS, Valle D (eds). The Metabolic Basis of Inherited Disease. McGraw-Hill, New York, pp 889-914

5. Allison F, Bennett MJ, Variend S, Engel PC 1988 Acylcoenzyme A dehydrogenase deficiency in heart tissue from infants who died unexpectedly with fatty change in the liver. Br Med J 296:11-12

6. Ikeda Y, Okamura-Ikeda K, Tanaka K 1985 Purification and characterization of short chain, medium chain, and long chain acyl-CoA dehydrogenases from rat liver mitochondria: isolation of the holo- and apoenzymes and conversion of the apoenzyme to the holoenzyme. J Biol Chem 260:13111325

7. Ikeda Y Tanaka K 1987 Immunoprecipitation and electrophoretic analysis of four human acyl-CoA dehydrogenases and electron transfer flavoprotein using antibodies raised against the corresponding rat enzymes. Biochem Med Metab Biol 37:329-334

8. Finocchiaro G, Ito M, Tanaka K 1987 Purification and properties of short chain acyl-CoA, medium chain acyl-CoA, and isovaleryl-CoA dehydrogenases from human liver. J Biol Chem 262:7982-7989

9. Naito E, Indo Y, Tanaka K I989 Short chain acyl-coenzyme A dehydrogenase (SCAD) deficiency. Immunochemical demonstration of molecular heterogeneity due to variant SCAD with differing stability. J Clin Invest 84:16711674
10. Bradford MM 1976 A rapid and sensitive method for the quantitation of microgram quantities of protein utilizing the principle of protein-dye binding. Anal Biochem 72:248-254

11. Laemmli UK 1970 Cleavage of structural proteins during the assembly of the head of bacteriophage T4. Nature 227:680-685

12. Towbin H, Staehelin T, Gordon J 1979 Electrophoretic transfer of proteins from acrylamide gels to nitrocellulose sheet: procedure and some applications. Proc Natl Acad Sci USA 76:4350-4354

13. Indo Y, Kitano A, Endo F, Akaboshi I, Matsuda I 1987 Altered kinetic properties of the branched-chain $\alpha$-keto acid dehydrogenase complex due to mutation of the $\beta$-subunit of the branched-chain $\alpha$-keto acid decarboxylase $\left(\mathrm{E}_{1}\right)$ component in lymphoblastoid cells derived from patients with maple syrup urine disease. J Clin Invest 80:63-70

14. Kelly DP, Kim JJ, Billadello JJ, Hainline BE, Chu TW, Strauss AW 1987 Nucleotide sequence of medium-chain acyl-CoA dehydrogenase mRNA and its expression in enzyme-deficient human issue. Proc Natl Acid Sci USA 84:4068-4072

15. Matsubara Y, Kraus JP, Ozasa H, Glassberg R, Finocchiaro G, Ikeda Y, Mole J, Rosenberg LE, Tanaka K 1987 Molecular cloning and nucleotide sequence of cDNA encoding the entire precursor of rat liver medium chain acyl coenzyme A dehydrogenase. J Biol Chem 262:10104-10108

16. Matsubara Y, Indo Y, Naito E, Ozasa H, Glassberg R, Vockley J, Ikeda Y, Kraus J, Tanaka K 1989 Molecular cloning and nucleotide sequence of cDNAs encoding the precursors of rat long chain acyl-coenzyme A, short chain acyl-coenzyme A, and isovaleryl-coenzyme A dehydrogenases. J Biol Chem 264:16321-16331

17. Furuta S, Miyazawa S, Hashimoto T 1981 Purification and properties of rat liver acyl-CoA dehydrogenases and electron transfer flavoprotein. J Biochem 90:1739-1750

18. Ikeda Y, Keese SM, Tanaka K 1985 Molecular heterogeneity of varian isovaleryl-CoA dehydrogenase from cultured isovaleric acidemia fibroblasts. Proc Natl Acad Sci USA 82:7081-7085

19. Naito E, Ozasa H, Ikeda Y, Tanaka K 1989 Molecular cloning and nucleotide sequence of complementary DNAs encoding human short chain acyl coenzyme A dehydrogenase and the study of the molecular basis of human short chain acyl-coenzyme A dehydrogenase deficiency. J Clin Invest 83:16051613

20. Naito E, Indo Y, Tanaka K 1990 Identification of two variant short chain acyl-coenzyme A dehydrogenase alleles, each containing a different point mutation in a patient with short chain acyl-coenzyme A dehydrogenase deficiency. J Clin Invest 85:1575-1582

21. Ikeda Y, Hale DE, Keese SM, Coates PM, Tanaka K 1986 Biosynthesis of variant medium chain acyl-CoA dehydrogenase in cultured fibroblasts from patients with medium chain acyl-CoA dehydrogenase deficiency. Pediatr Res 20:843-847

22. Yokota I, Indo Y Coates PM, Tanaka K 1990 Molecular basis of medium chain acyl-coenzyme A dehydrogenase deficiency. An A to $G$ transition at position 985 that causes a lysine-304 to glutamate substitution in the mature protein is the single prevalent mutation. J Clin Invest 86:1000-1003 